\title{
ANALISIS KEUNGGULAN SEKOLAH DASAR SWASTA BERDASARKAN STANDAR NASIONAL PENDIDIKAN DENGAN MENGGUNAKAN METODE BIPLOT
}

\author{
Usep Rahmat \\ Program Studi Matematika FMIPA Universitas Pamulang \\ Email: usep.rahmat@yahoo.com
}

\begin{abstract}
The aim of this research was conducted to map the relative position, advantages and characteristics of private elementary schools in District Bojongsari Depok based standard indicators of education and educational personnel, facilities and infrastructure standard, educational assessment standards. The research data was obtained from a sample of five Elementary Schools in District Bojongsari Depok and the Office of National Education of District Bojongsari Depok. Variables used were the standard variables of education and educational staff, standard of facilities and infrastructure variable, educational assessment standards. Data analysis was performed using SAS 9.13. The results showed that the schools relative position in the district Bojongsari is very competitive and the schools are categorized already have good exellence based on standard of education and educational personnel, facilities and infrastructure standard, educational assessment standards are SDIT Az-Zahra, SDI Nurul Hidayah, SDIT AMEC. Schools that have a poorer exxellence of SDI Azmia dan SD Tadikapuri. One School exxelence have characteristics but four school have not exxelence and characteristic becaused diversity very small.
\end{abstract}

Keywords : Biplot method, Elementary School, Relative Position, Advantage, Characteristics

\begin{abstract}
Abstrak
Penelitian ini dilakukan dengan tujuan untuk memetakan posisi relatif, keunggulan serta ciri SD-SD swasta di Kecamatan Bojongsari berdasarkan indikator standar pendidikan dan tenaga kependidikan, standar sarana dan prasarana, standar penilaian pendidikan. Data penelitian ini diperoleh dari sampel 5 SD Swasta di Kecamatan Bojongsari dan UPTP Kecamatan Bojongsari. Peubah yang digunakan adalah peubah standar pendidikan dan tenaga kependidikan, peubah standar sarana dan prasarana, peubah standar penilaian pendidikan. Analisis data dilakukan dengan Metode Biplot yang menggunakan perangkat lunak SAS 9.13. Hasil analisisnya menunjukkan bahwa posisi relatif sekolah-sekolah di Kecamatan Bojongsari sangat bersaing kompetitif dan sekolah yang dikategorikan sudah memiliki keunggulan berdasarkan standar pendidikan dan tenaga kependidikan, standar sarana dan prasarana, standar penilaian pendidikan yaitu SDIT Az-Zahra, SDI Nurul Hidayah, SDIT AMEC. Sedangkan sekolahsekolah yang belum memiliki keunggulan yang cukup baik yaitu SDI Azmia dan SD Tadikapuri. Hanya satu sekolah yang unggul memiliki penciri tiga SNP, namun 4 sekolah belum memiliki keunggulan tiga SNP dikarenakan keragaman peubah sangat kecil.
\end{abstract}

Kata Kunci : Metode Biplot, Sekolah Dasar, Posisi Relatif, Keunggulan, Penciri

\section{PENDAHULUAN}

Tingkat satuan pendidikan yang dianggap sebagai dasar pendidikan adalah sekolah dasar. Disekolah inilah anak didik mengalami proses pendidikan dan pembelajaran. Pada umumnya setiap sekolah dasar akan mempunyai sifat dan ciri yang khas, seperti kualifikasi pendidik dan tenaga kependidikan, letak sekolah, kondisi sekolah dan sarana prasarana serta nilai tertinggi yang dihasilkan dari siswa sekolah tersebut. Keadaan ini biasanya dijadikan dasar penilaian oleh orang tua, dikarenakan pendidikan yang baik akan mempengaruhi kemampuan penyesuaian sosial siswa dalam beradaptasi dengan lingkungan sekolahnya yang penting bagi keberhasilan di masa datang.

Berkembang pesatnya dunia pendidikan saat ini telah membawa berbagai perubahan. Perubahan yang nyata adalah beragamnya jenis pendidikan sekolah dasar yang menjanjikan banyak keunggulan yang dimiliki sekolah tersebut. Banyaknya sekolah dasar yang menjanjikan keunggulan tersebut menyebabkan mereka semakin kompetitif dalam bersaing untuk menarik perhatian para orang tua. Mengingat persaingan yang semakin kompetitif, maka suatu sekolah dasar perlu melakukan perbaikan 
dan pembaharuan yang berkesinambungan agar tetap dapat mempertahankan berdirinya sekolah tersebut.

Sedangkan acuan yang digunakan untuk melihat keunggulan pendidikan pada satuan pendidikan adalah Standar Nasional Pendidikan (SNP) dan standar-standar lain yang disepakati oleh kelompok masyarakat. Standar Nasional Pendidikan sebagaimana yang diatur dalam Peraturan Pemerintah Nomor 19 Tahun 2005 tentang Standar Nasional Pendidikan dan peraturan perundangan lain yang relevan yaitu kriteria minimal tentang sistem pendidikan di seluruh wilayah hukum Negara Kesatuan Republik Indonesia.

Standar nasional pendidikan terdiri dari 8 standar, yaitu Standar Kompetensi Lulusan, Standar Isi, Standar Proses, Standar Pendidikan dan Tenaga Kependidikan, Standar Sarana dan Prasarana, Standar Pengelolaan, Standar Pembiayaan Pendidikan dan Standar Penilaian Pendidikan.

Jadi, berdasarkan latar belakang diatas, untuk mengetahui keunggulan sekolah dasar swasta akan diperlukan penelitian untuk melihat persaingan, keunggulan, dan ciri dari sekolah dasar swasta yang berdasarkan Standar Nasional Pendidikan (SNP). Penelitian ini dianalisis dengan menggunakan metode Biplot agar dapat menyajikan secara simultan dalam bentuk gambar dua dimensi antara indikator Standar Nasional Pendidikan (sebagai peubah) dengan SD-SD swasta (sebagai objek). Dengan dasar pemikiran itulah peneliti termotivasi untuk melaksanakan penelitian tentang "Analisis Keunggulan Sekolah Dasar Swasta Berdasarkan Standar Nasional Pendidikan Dengan Menggunakan Metode Biplot ".

\section{METODE PENELITIAN}

\subsection{Tempat Penelitian}

Penelitian di lima sekolah dasar swasta di Kecamatan Bojongsari dan di kantor Unit Pelaksanaan Teknis Pendidikan (UPTP) TK/SD Bojongsari yang berlokasi di Jalan Raya Curug Bojongsari Kota Depok Propinsi Jawa Barat.

\subsection{Populasi dan Sampel}

Populasi target adalah populasi yang menjadi sasaran akhir penerapan hasil penelitian (Dahlan, 2008). Populasi target pada penelitian ini adalah seluruh sekolah dasar swasta di Kota Depok Jawa Barat, populasi terjangkau adalah bagian dari populasi target yang dapat dijangkau oleh peneliti yang dibatasi ruang dan waktu (Dahlan, 2008). Populasi terjangkau pada penelitian ini adalah seluruh sekolah dasar swasta di Kecamatan Bojongsari Kota Depok Propinsi Jawa Barat.

Sampel yang digunakan dalam penelitian ini adalah 5 SD swasta di Kecamatan Bojongsari Depok Jawa Barat dimana sekolah tersebut memiliki data yang dibutuhkan oleh peneliti dan bersedia untuk memberikan data. Adapun sekolah-sekolah yang bersedia untuk memberikan datanya dan bersedia untuk menjadi sampel yaitu :

\subsection{Variabel Penelitian}

Variabel yang diamati adalah variabel standar nasional pendidikan yang terdiri dari standar Pendidikan dan Tenaga Kependidikan, Standar Sarana dan Prasarana, serta Standar Penilaian Pendidikan. Variabel penelitian seluruhnya berjumlah enam belas. Variabel-variabel yang diamati disajikan pada tabel-tabel berikut ini : 
Tabel 3.1 Variabel Standar Pendidikan dan Tenaga Kependidikan

\begin{tabular}{cl}
\hline Kode & \multicolumn{1}{c}{ Nama Variabel } \\
\hline $\mathrm{X}_{1}$ & Jumlah masing-masing guru \\
$\mathrm{X}_{2}$ & Jumlah tenaga administrasi \\
$\mathrm{X}_{3}$ & Jumlah tenaga perpustakaan \\
$\mathrm{X}_{4}$ & Jumlah tenaga kantin \\
$\mathrm{X}_{5}$ & Jumlah tenaga kebersihan \\
\hline
\end{tabular}

Tabel 3.2 Variabel Standar Sarana dan Prasarana

\begin{tabular}{cl}
\hline Kode & \multicolumn{1}{c}{ Nama Variabel } \\
\hline $\mathrm{X}_{6}$ & Luas lahan \\
$\mathrm{X}_{7}$ & Jumlah seluruh siswa \\
$\mathrm{X}_{8}$ & Jumlah komputer \\
$\mathrm{X}_{9}$ & Jumlah WC \\
$\mathrm{X}_{10}$ & Jumlah rombel \\
$\mathrm{X}_{11}$ & Jumlah ruang pimpinan \\
$\mathrm{X}_{12}$ & Jumlah ruang guru \\
$\mathrm{X}_{13}$ & Jumlah ruang kelas \\
$\mathrm{X}_{14}$ & Jumlah OHP/LCD \\
$\mathrm{X}_{15}$ & Jumlah loker \\
\hline
\end{tabular}

Tabel 3.3 Variabel Standar Penilaian Pendidikan

\begin{tabular}{cc}
\hline Kode & Nama Variabel \\
\hline $\mathrm{X}_{16}$ & Nilai rata-rata UASBN Tertinggi \\
\hline
\end{tabular}

\subsection{Teknik Analisis Data}

Metode analisis yang dilakukan dalam penelitian ini adalah analisis Biplot. Pengolahan data dilakukan dengan menggunakan makro SAS 9.1.3. Input untuk data Biplot adalah matrik rataan yaitu mariks yang berisi rataan dari setiap peubah pada setiap objek atau matriks data dari $n$ objek dan $p$ peubah itu sendiri. Struktur data yang dapat dianalisis dengan metode Biplot diperlihatkan oleh Tabel 3.4 . 
Tabel 3.4 Struktur Data yang dapat dianalisis dengan Metode Biplot

\begin{tabular}{cccccc}
\hline \multirow{2}{*}{$\begin{array}{c}\text { Nama } \\
\text { Sekolah }\end{array}$} & \multicolumn{5}{c}{ Peubah ke- } \\
\cline { 2 - 6 } & 1 & 2 & 3 & $\ldots$ & $\mathrm{M}$ \\
\hline 1 & $\mathrm{X}_{11}$ & $\mathrm{X}_{12}$ & $\mathrm{X}_{13}$ & $\ldots$ & $\mathrm{X}_{1 \mathrm{~m}}$ \\
2 & $\mathrm{X}_{21}$ & $\mathrm{X}_{22}$ & $\mathrm{X}_{23}$ & $\ldots$ & $\mathrm{X}_{2 \mathrm{~m}}$ \\
3 & $\mathrm{X}_{31}$ & $\mathrm{X}_{32}$ & $\mathrm{X}_{33}$ & $\ldots$ & $\mathrm{X}_{3 \mathrm{~m}}$ \\
$\ldots$ & $\ldots$ & $\ldots$ & $\ldots$ & $\ldots$ & $\ldots$ \\
$\mathrm{N}$ & $\mathrm{X}_{\mathrm{n} 1}$ & $\mathrm{X}_{\mathrm{n} 2}$ & $\mathrm{X}_{\mathrm{n} 3}$ & $\ldots$ & $\mathrm{X}_{\mathrm{nm}}$ \\
\hline
\end{tabular}

\section{Keterangan :}

$\mathrm{N}=$ Jumlah pesaing SD swasta sekitarnya

$\mathrm{M}=$ Jumlah peubah pengamatan

$X_{n m}=$ Skala penilaian pada $\mathrm{m}$

\subsection{Tahapan-tahapan Analisis Biplot}

Adapun langkah-langkah analisisnya sebagai berikut:

2.5.1. Pemasukan data matrix $X$ (data rata-rata variabel pengamatan)

$$
\mathrm{X}=\left[\begin{array}{cccc}
X_{11} & X_{12} & \ldots & X_{1 p} \\
X_{21} & X_{22} & \ldots & X_{2 p} \\
\vdots & \vdots & \ddots & \vdots \\
X_{n 1} & X_{n 2} & \ldots & X_{n p}
\end{array}\right]
$$

Baris menunjukan sekolah, sedangkan kolom menunjukan variabel ( unit indikator SNP).

2.5.2. Koreksi tiap peubah terhadap rataannya.

$$
\mathrm{X}=\left[\begin{array}{cccc}
x_{11}-\bar{x}_{1} & x_{12}-\bar{x}_{2} & \ldots & x_{1 p}-\bar{x}_{p} \\
x_{21}-\bar{x}_{1} & x_{22}-\bar{x}_{2} & \ldots & x_{2 p}-\bar{x}_{p} \\
\vdots & \vdots & \ddots & \vdots \\
x_{n 1}-\bar{x}_{1} & x_{n 2}-\bar{x}_{2} & \ldots & x_{n p}-\bar{x}_{p}
\end{array}\right]
$$

2.5.3. Menghitung matriks korelasi dari matriks rataan X (dengan software Minitab 14.0)

2.5.4. Cari X' X

2.5.5. Cari akar ciri dan vektor cirinya, kemudian diurutkan akar cirinya (dengan software Minitab 14.0)

2.5.6. Penguraian matriks X oleh Singular Value Decomposition

2.5.7. Cari Matriks L, A, U

$$
L=\left[\begin{array}{cccc}
\sqrt{\lambda_{1}} & \cdots & \cdots & 0 \\
0 & \sqrt{\lambda_{2}} & \cdots & 0 \\
\vdots & \vdots & \ddots & \vdots \\
0 & 0 & \cdots & \sqrt{\lambda_{r}}
\end{array}\right]
$$


Selanjutnya disusun matriks $\mathrm{U}$

$$
U=\left\{\frac{1}{\sqrt{\lambda_{1}}} X a_{1}, \frac{1}{\sqrt{\lambda_{2}}} X a_{2}, \ldots, \frac{1}{\sqrt{\lambda_{r}}} X a_{r}\right\}
$$

Matriks U dihitung melalui persamaan $\frac{\mathbf{1}}{\sqrt{\lambda_{\mathbf{i}}}} \mathbf{X a}_{\mathbf{i}}$, dengan $\boldsymbol{\lambda}_{\boldsymbol{i}}$ adalah akar ciri ke-i dari matriks $X^{\prime} \mathrm{X}$ dan $a_{i}$ adalah lajur ke- $i$ matriks A. (dengan software Minitab 14.0)

2.5.8. Cari nilai $\mathrm{G}$ dan $\mathrm{H}$ (dengan software SAS 9.1.3)

2.5.9. Menghitung koefisien kebaikan biplot sesuai dari dua akar ciri terbesar.

$$
p^{2}=\frac{\left(\lambda_{1}+\lambda_{2}\right)}{\sum \lambda_{i}}
$$

Dengan $\lambda 1=$ akar ciri terbesar pertama

Dengan $\lambda_{2}=$ akar ciri terbesar kedua

Dengan $\lambda_{\mathrm{i}}=$ akar ciri terbesar ke- $i$

Jika nilai dari $\chi^{2}$ mendekati nilai satu, berarti biplot yang diperoleh dari matriks akan memberikan penyajian data yang semakin baik mengenai informasiinformasi yang terdapat pada data yang sebenarnya.

Analisis Biplot dapat dilakukan dengan menggunakan perangkat lunak SAS (Statistical Analysis Sistem) versi 9.1.3

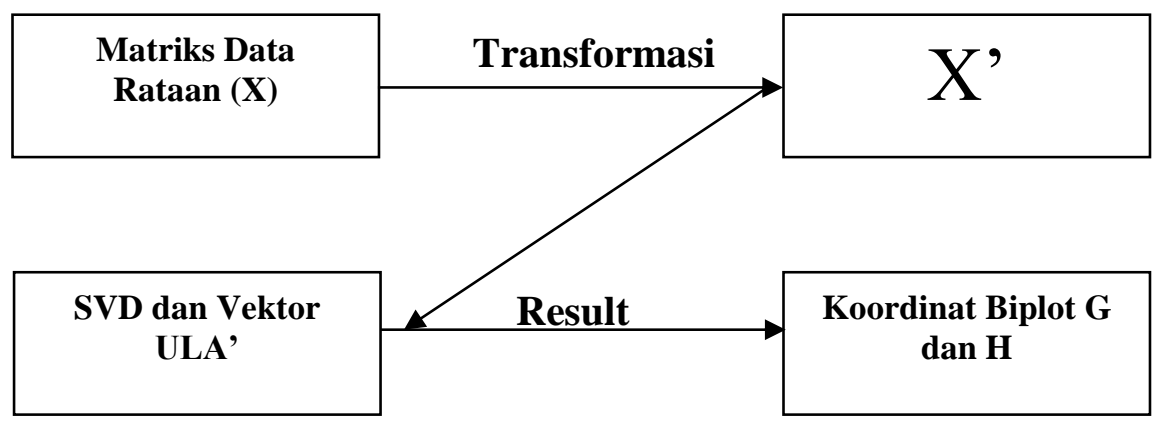

Gambar 3.1 Diagram Alur Analisis Biplot

\section{HASIL ANALISIS}

\subsection{Analisis Biplot pada STP dengan SPP}

Dalam matriks data rataan X berisi 6 variabel dari STP dan SPP, dimana 6 variabel tersebut adalah $\mathrm{X}_{1}$ ( Jumlah Guru ), $\mathrm{X}_{2}$ (Jumlah Pegawai Administrasi), $\mathrm{X}_{3}$ (Jumlah Pegawai Perpustakaan), $\mathrm{X}_{4}$ (Jumlah Pegawai Kantin), $X_{5}$ (Jumlah Tenaga Kebersihan), dan $X_{16}$ ( Nilai Rata-rata UASBN Tertinggi).

a) Matriks Rataan

$X=\left|\begin{array}{cccccc}10.75 & 1.5 & -0.25 & 1.8 & 7 & 0.528 \\ 4.75 & 0.5 & -0.25 & 0.8 & 1 & 0.228 \\ -7.25 & -0.5 & 0.75 & -1.2 & -3 & 0.028 \\ -8.25 & -1.5 & -0.25 & -1.2 & -5 & -0.472 \\ -6.25 & -0.5 & 0.75 & -0.2 & -4 & -0.312\end{array}\right|$


b) Nilai $X^{\prime} X$

$$
\mathrm{X}^{\prime} \mathrm{X}=\left|\begin{array}{cccccc}
297.813 & 37.625 & -11.938 & 43 & 168 & 12.4 \\
37.625 & 5.25 & -0.875 & 5.6 & 22 & 1.756 \\
-11.938 & -0.875 & 1.3125 & -1.4 & -6 & -0.284 \\
43 & 5.6 & -1.4 & 6.8 & 23.8 & 1.728 \\
168 & 22 & -6 & 23.8 & 100 & 7.448 \\
12.4 & 1.756 & -0.284 & 1.728 & 7.448 & 0.6517
\end{array}\right|
$$

\section{c) Nilai Eigenvalue dari $X^{\prime} X$}

Nilai eigenvalue yang diperoleh adalah 405.810442, 4.3162461, 1.34557902, 0. 32562188, 0.02937528, dan 0.000064972. Matriks L diperoleh dengan menggunakan rumus $I_{i}=\sqrt{\lambda_{i}}$.

$$
\mathrm{L}=\left|\begin{array}{rrrrrr}
20.14477 & 0 & 0 & 0 & 0 & 0 \\
0 & 2.07755 & 0 & 0 & 0 & 0 \\
0 & 0 & 1.15999 & 0 & 0 & 0 \\
0 & 0 & 0 & 0.570632 & 0 & 0 \\
0 & 0 & 0 & 0 & 0.171392 & 0 \\
0 & 0 & 0 & 0 & 0 & 8 \times 10^{-4}
\end{array}\right|
$$

Dengan menggunakan program Minitab 14.0 diperoleh matriks eigenvector yang merupakan kolom matrik A.

$$
A=\left|\begin{array}{cccccc}
-0.855308 & -0.46435 & 0.008581 & 0.182042 & -0.07017 & -0.12123 \\
-0.109141 & 0.135049 & -0.47534 & 0.316572 & -0.15882 & 0.786422 \\
0.033182 & 0.213505 & -0.69385 & 0.245036 & -0.23438 & -0.59742 \\
-0.123137 & -0.1563 & -0.50019 & -0.78831 & 0.286294 & 0.082573 \\
-0.488839 & 0.829557 & 0.177698 & -0.20211 & 0.002646 & -0.021 \\
-0.036185 & 0.089256 & -0.10386 & 0.379886 & 0.91266 & -0.05173
\end{array}\right|
$$

\section{d) Nilai G dan $\mathbf{H}$}

Dengan menggunakan program SAS 9.1.3. Dari pendekatan matriks X pada dimensi dua, matriks $\mathrm{G}$ dan $\mathrm{H}^{\prime}$ diperoleh adalah sebagai berikut ini :

$$
G=\left|\begin{array}{cc}
3.2536 & 0.5632 \\
1.3905 & -0.9686 \\
-1.4399 & 0.8458 \\
-1.8724 & -0.2695 \\
-1.3318 & -0.1709
\end{array}\right|
$$




\begin{tabular}{|c|c|c|c|c|c|c|c|}
\hline & $\mathrm{H}^{\prime}=$ & 3.8139 & 0.4916 & -0.1395 & 0.5641 & 2.1726 & 0.1658 \\
\hline & & -0.6689 & 0.2062 & 0.3256 & -0.2019 & 1.1906 & 0.1355 \\
\hline
\end{tabular}
merupakan titik koordinat dari 5 objek dan matrik H merupakan titik koordinat dari 6 variabel.

\section{e) Gambar Grafik Biplot}

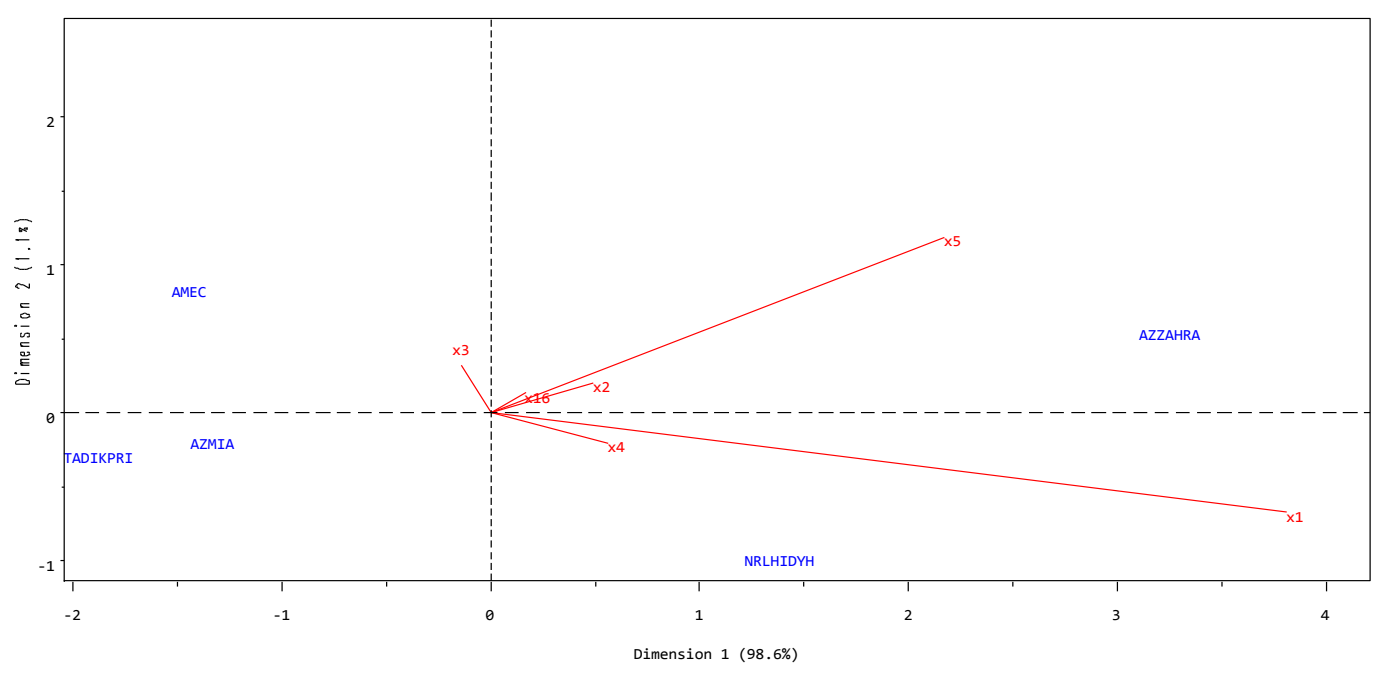

\section{Gambar 4.1. Biplot Standar Pendidikan dan Tenaga Kependidikan dan Standar Penilaian} Pendidikan

\section{Keterangan :}

$\mathrm{X}_{1} \quad=$ Jumlah Guru

$\mathrm{X}_{2} \quad=$ Jumlah Pegawai Administrasi

$\mathrm{X}_{3} \quad=$ Jumlah Pegawai Perpustakaan

$\mathrm{X}_{4} \quad=$ Jumlah Pegawai Kantin

$\mathrm{X}_{5} \quad=$ Jumlah Tenaga Kebersihan

$\mathrm{X}_{16} \quad=$ Nilai Rata-rata UASBN Tertinggi

Dengan menjalankan program makro Biplot melalui software SAS 9.1.3, maka diperoleh tampilan Biplot seperti pada gambar 4.1 .

\section{f) Interpretasi Biplot}

Pada Gambar 4.1, terlihat bahwa SD Tadikapuri dan SDI Azmia posisinya saling berdekatan. Hal ini berarti bahwa kedua sekolah tersebut relatif sama. Sedangkan SDIT Az-Zahra, SDIT AMEC, SDI Nurul Hidayah posisinya relatif tidak berdekatan.

Terlihat ada beberapa objek (SD) yang posisi titiknya agak jauh dari vektor-vektor variabel yang ada. Objek-objek tersebut diantaranya, SD Tadikapuri, SDI Azmia, dan SDIT AMEC. Hal ini berarti bahwa ketiga sekolah tersebut dapat dikategorikan sebagai sekolah yang belum memiliki keunggulan Standar Pendidik dan Tenaga Kependidikan dan Standar Penilaian Pendidikan. Sedangkan objek yang lain seperti SDIT Az-Zahra dan SDI Nurul Hidayah dikategorikan sebagai 
sekolah yang masing-masing sudah memiliki keunggulan Standar Pendidik dan Tenaga Kependidikan dan Standar Penilaian Pendidikan .

Keragaman yang besar terjadi pada variabel jumlah guru $\left(\mathrm{X}_{1}\right)$ dan jumlah tenaga kebersihan $\left(\mathrm{X}_{5}\right)$ karena variabel-variabel tersebut memiliki vektor yang panjang. Hal ini menunjukan bahwa SDSD swasta di Kecamatan Bojongsari sangat beragam dalam hal jumlah guru dan jumlah tenaga kebersihan. Sedangkan keragaman terkecil terjadi pada variabel nilai rata-rata UASBN $\left(\mathrm{X}_{16}\right)$ karena memiliki vektor yang paling pendek.

Gambar 4.1 terlihat bahwa SDIT Az-Zahra merupakan sekolah yang unggul dalam hal jumlah tenaga administrasi $\left(\mathrm{X}_{2}\right)$, jumlah guru $\left(\mathrm{X}_{1}\right)$, jumlah tenaga kebersihan $\left(\mathrm{X}_{5}\right)$, dan nilai rata-rata UASBN tertinggi $\left(\mathrm{X}_{16}\right)$ karena vektor dari keempat variabel tersebut searah dengan SDIT Az-Zahra. SDIT AMEC merupakan sekolah yang unggul dalam hal jumlah tenaga perpustakaan. SDI Nurul Hidayah merupakan sekolah yang unggul dalam hal jumlah tenaga kantin $\left(\mathrm{X}_{4}\right)$. Sedangkan SDI Azmia dan SD Tadikapuri merupakan sekolah yang belum unggul dalam keseluruhan variabel tersebut.

g) Ukuran Koefisien Kebaikan Biplot

$$
\begin{aligned}
p^{2} & =\frac{\left(\lambda_{1}+\lambda_{2}\right)}{\sum \lambda_{i}} \\
& =\frac{(405.810442+4.3162461)}{411.8271994}=0.9958
\end{aligned}
$$

Karena nilai $p^{2}$ yang diperoleh mendekati nilai 1, berarti biplot yang dihasilkan sangat baik. Informasi yang diberikan oleh biplot sebesar $99.58 \%$ dari keseluruhan informasi yang terkandung dalam data.

\subsection{Analisis Biplot Standar Sarana dan Prasarana I}

Dengan cara yang sama seperti point 3.1 diperoleh analisis Biplot Standar dan Prasarana I sebagai berikut :

$$
\begin{aligned}
p^{2} & =\frac{\left(\lambda_{1}+\lambda_{2}\right)}{\sum \lambda_{i}} \\
& =\frac{(4674404.8686+47315.185109)}{4721794.29999005}=0.9999
\end{aligned}
$$

Karena nilai $p^{2}$ yang diperoleh mendekati nilai 1, berarti biplot yang dihasilkan sangat baik. Informasi yang diberikan oleh biplot sebesar $99.99 \%$ dari keseluruhan informasi yang terkandung dalam data.

\subsection{Analisis Biplot Standar Sarana dan Prasarana II}

$$
\begin{aligned}
p^{2} & =\frac{\left(\lambda_{1}+\lambda_{2}\right)}{\sum \lambda_{i}} \\
& =\frac{(762.77048221+43.43509100)}{807.79999998}=0.9980
\end{aligned}
$$

Karena nilai $p^{2}$ yang diperoleh mendekati nilai 1, berarti biplot yang dihasilkan sangat baik. Informasi yang diberikan oleh biplot sebesar $99.80 \%$ dari keseluruhan informasi yang terkandung dalam data. 


\subsection{Variabel Penciri Sekolah Dasar Swasta}

Berdasarkan Biplot yang ditampilkan dalam gambar 4.1, gambar 4.2, dan gambar 4.3 maka terlihat variabel mana yang memberikan sumbangan keragaman yang relatif besar terhadap masing-masing sekolah yang selanjutnya disebut sebagai variabel penciri dari sekolah tersebut. Masing-masing sekolah memiliki penciri yang berbeda pada setiap variabelnya, variabel dalam kelompok 1 merupakan penciri dari SDIT Az-Zahra. Hal ini dapat ditinjau dari keunggulan dan kelengkapan STP, SarPras, dan SPP pada sekolah ini dan dibuktikan dengan banyaknya jumlah siswa pada sekolah ini. variabel dalam kelompok 2 merupakan penciri dari SDI Nurul Hidayah. Jumlah tenaga perpustakaan $\left(\mathrm{X}_{3}\right)$ merupakan variabel penciri dari sekolah SDIT AMEC yang berada di kelompok 3. Sedangkan tidak ada variabel dalam kelompok 4 yang seharusnya penciri dari sekolah SDI Azmia dan SD Tadikapuri. Ini berarti variabel yang dimiliki dua sekolah tersebut mempunyai nilai keragaman yang kecil atau bisa dikatakan relatif sama.

\section{KESIMPULAN DAN SARAN}

Berdasarkan pada bab hasil dan pembahasan, maka dapat disimpulkan beberapa hal berdasarkan perumusan masalah, yaitu :

1) Posisi objek (SD-SD Swasta) berdasarkan variabel penelitian (indikator SNP) yang di tampilkan melalui hasil analisis biplot dalam dimensi 2 dapat terlihat bahwa SD Tadikapuri dan SDI Azmia posisinya saling berdekatan. Sedangkan SDIT Az-Zahra, SDIT AMEC, SDI Nurul Hidayah posisinya saling berjauhan.

2) Satu SD swasta di Kecamatan Bojongsari memiliki keunggulan 3 SNP yaitu SDIT Az-Zahra dan 4 sekolah belum memiliki keunggulan 3 SNP.

3) Variabel penciri dapat di kelompokan menjadi 4 kelompok, yaitu :

a. Kelompok 1 yang terdiri dari 9 variabel yang merupakan variabel penciri dari SDIT Az-Zahra.

b. Kelompok 2 terdiri dari 2 variabel yang merupakan variabel penciri dari SDI Nurul hidayah.

c. Kelompok 3 yang terdiri dari 1 variabel merupakan variabel penciri dari SDIT AMEC.

d. Kelompok 4 tidak memiliki variabel penciri yaitu SDI Azmia dan SD Tadikapuri.

Saran yang dapat dikemukakan dalam penelitian ini yaitu:

1) Dengan melihat posisi relatif pada grafik biplot, maka setiap sekolah dasar swasta dapat mengevaluasi indikator-indikator SNP, terutama pada Standar Sarana dan Prasarana (SarPras) dan Standar Penilaian Pendidikan (SPP) agar jumlah murid dapat meningkat setiap tahun ajaran barunya serta mengevaluasi unit indikator lainnya yang relatif sama dimana tidak ada perbedaan secara signifikan dengan sekolah lain. Sedangkan sekolah dasar swasta yang sudah unggul pada 3 SNP tersebut tetap dapat melakukan evaluasi yang berkesinambungan agar bisa mempertahankan keunggulannya.

2) Berdasarkan variabel penciri masing-masing kelompok dapat dijadikan acuan untuk masyarakat khususnya orang tua untuk memilih sekolah dasar swasta yang tepat untuk anaknya, dan juga dapat dijadikan sebagai acuan pada indikator mana pembangunan pendidikan pada sekolah-sekolah terkait yang harus dilaksanakan.

3) Untuk menyempurnakan penelitian ini, dalam menganalisis sekolah dasar swasta di Kecamatan Bojongsari, dapat menambahkan variabel-variabel lain yang secara signifikan dijadikan pertimbangan bagi masyarakat khususnya orang tua dalam menentukan pilihan SD swasta di Kecamatan Bojongsari Kota Depok.

\section{DAFTAR PUSTAKA}

Ansori Ahmad M., dan Made I S., 2011. Sidik Peubah Ganda Dengan

Menggunakan SAS. Bogor: IPB Press.

Dahlan, Sopiyudin M, 2008. Langkah-Langkah Membuat Proposal Penelitian Bidang Kedokteran dan Kesehatan. Jakarta : Sagung Seto. 
Gabriel, K R., 1971. The Biplot-Graphic Display of Matrices With Application to Principal Component Analysis. Jerussalem : Biometrika.

Gazali Wikaria, 2005. Matriks dan Transformasi Linier, Yogyakarta: PT. Graha Ilmu.

Greenacre MJ. 1984. Theory and Application of Correspondence Analysis. London: Academic Press, Inc.

Hatidja, DJ., dan Daman Redianus, 2012. "Pemetaan SMP-SMP di Kabupaten Minahasa Tenggara, Sulawesi Utara Berdasarkan Standar Pendidikan dan Tenaga Kependidikan, Standar Sarana dan Prasarana, Standar Pengelolaan dan Standar Pembiayaan Pendidikan Dengan Menggunakan Analisis Biplot”, Jurnal Ilmiah Sains. Vol. 1. No. 1:27-35.

http://ronawajah.wordpress.com.2007. Keunggulan Kompetitif.Oleh Sjafri Mangkuprawira,

Johnson, Richard A., Wichern, Dean W., 2002. Applied Multivariate Statistical Analysis.

Prentice Hall : Fifth Edition.

Jollife, I. T., 1986. Principal Component Analyisis. Newyork: Springer Verlag.

Melissa, 2012. Pendekatan Analisis Biplot Dalam Mendeskripsikan Posisi Relatif Antar SMA Di Kota Denpasar. e-Jurnal Matematika. Vol. 1. No. 1. 47-51.

Mulyasa, 2009. Implementasi KTSP. Jakarta: PT. Bumi Aksara.

Sartono, dkk. 2003. Analisis Peubah Ganda. Bogor: Jurusan Statistika FMIPA IPB.

Siswadi dan Budi Suharjo.1999. Analisis Eksplorasi Data Peubah Ganda. Bogor: Jurusan Matematika FMIPA IPB Bogor.

Sugiyono. 2003. Metode Penelitian Bisnis. Bandung: Pusat Bahasa Depdiknas. 